\title{
Wechat Online Purchase Intention
}

\author{
Kagabo Dieudonne ${ }^{1, a^{*}}$, Zhong $\mathrm{YaO}^{2, \mathrm{~b}}$ and Hao $\mathrm{Liu}^{3, \mathrm{c}}$ \\ School of Economics and Management, Beihang University, Beijing 100191, China \\ alb1308204@buaa.edu.cn, biszhyao@buaa.edu.cn, 'liubao@buaa.edu.cn
}

\begin{abstract}
Keywords: Social commerce; Wechat; Perceived convenience of use; Online purchase intention
\end{abstract}
\begin{abstract}
Social commerce consumers increasingly rely on one hand by opinions and experiences shared by others especially individuals they trust and respect; on the other hand they rely on the effortless, convenience and easy process of a platform with some guarantee. This study investigates the impact of friendships towards trust of reviews and recommendations, third party services towards perceived ease of use and convenience of use acting as pipes to enhance online purchase intention and transactions. Using a survey through a growing and top social media in China Wechat (Weixin in Chinese) we test and analyse the research model and its related hypotheses using structural equation modelling. Data were collected from a survey which was sent through Wechat users. The empirical findings show that the perceived convenience of use affects online purchase intention. The results further show that friendship and third party services can moderate the effects on trust of reviews, recommendation and perceived ease of use, perceived convenience of use respectively very important factors in explanation of the individual's online purchase and transactions intention.
\end{abstract}

\section{Introduction}

Wechat is a Chinese instant messaging service that encompasses with more features with value added booking services (taxi, train, flight etc...), and food ordering, top up mobile phone, as well as a payment system. Wechat has 600 million monthly active users (MAUs), and has become a central component of a user's life. It was launched firstly as a social media now it implies a lot of businesses facilities. Business activities conducted through social media such as Wechat are called social commerce or social shopping [1]. Social commerce is a new expansion of e-commerce Due to various issues such as the absence of personal contact, the impossibility of physical products to be evaluated, lack of solid transaction to be protected, and data privacy; the issue of trust has become increasingly problematic for the customers. Dan et al. (2008)[2] has prove that trust, perceived risk, and perceived benefit may directly influence purchase intentions and decisions, and trust may also influence purchase intentions indirectly by influencing risk perceptions. Most important thing nowadays more and more customers are using mobile devices to conduct business activities gaining trust is serious challenged by interface design [3] and its network capabilities [4]. Koufaris and Hampton-Sosa (2004) [5] found that a customer perception about the website is a key determinant of gaining initial trust, followed by development of a buyer-seller relationship. Increase in social networks, the trust may be strengthened, so the consumer's purchasing intention can be increased. The social network service running on mobile phone has provided a significant convenience for shopping activities of users as it can be done anywhere at any time. However, we think that under SNS condition, particularly the social commerce, the convenience of use could be a new construct to affect the purchasing intentions.

In summary, we believed that a thorough examination of social factors and technical features such as friendship, trust recommendations from friends and companies, trust of reviews from users, third party services, perceived ease of use and perceived convenience of use, factors may promote or have implications on purchase intentions and transaction through SNS such as Wechat.

This paper is organized as follows. The following section concerns hypotheses development and Research model of this study in section 2. Our data collection, findings and implications are provided in section 3. In the last section we conclude with a presentation of the limits of this paper. 


\section{Hypotheses Development and Research Model}

We denote perceived convenience of use, friendship and third party services as critical role in enhancing Wechat users of online purchase and transactions intention. Figure 1 shows the research model, including the major theoretical constructs and their hypothesized relationships.

Friendships have an affective foundation as opposed to an economic foundation. Such relationships are governed by mutual, reciprocated affect rather than reciprocated economic exchange. As Argyle and Henderson (1984), in friendship relationships "receiving benefits does not incur a specific debt to return a comparable benefit, and does not alter the general obligation to aid the other in need. Thus, we propose the following hypotheses:

H1: The Friendship moderates the effect of the trust of reviews on online purchase intention.

H2: The Friendship moderates the effect of the trust of recommendation from friends and firms on online purchase intention.

Reviews are one constructs that shape social commerce. Individuals can easily post their product reviews online and rate products [6]. Research shows that a popular product review by a third party is growing (Yubo and Jinhong, 2005) [7]. Also the engagement of consumers in co-creation and content generation empowers those social media technology, facilitate consumers 'ratings and reviews as well. [8]

H3: The trusts of reviews are positively influencing the intention for online purchase intention

Social media are the most popular online activities, with a huge amount of the population actively involved. More than 20\% of online advertisements appear on social network sites [9]. Many businesses are exploiting the new web based tools in order to achieve fast and efficient information on consumers' needs and preferences. More often firms give coupons to membership users for promotion and some social media offer to users a portrail to share and recommend the best they like while shopping.

H4: The trusts of recommendations are positively influencing online purchase intention

Social channels correspond to the endogenous spaces which are provided by websites for users to interact with each other and to establish a trust network. For example, in terms of service factor Wu and Wang (2011) [10] discovered that the service function of social media platforms allow users to interact with each other and maintain online relationship, which is a significant predictor of behaviour intentions. Ammar et al (2014) [11] define easy to use of a platform as the degree in which a person trusts a particular system to be effortless as a conceptual definition and as operational definition is the degree to which the social commerce site is perceived as easy and effortless.

H5: The perceived ease of use is positively influencing online purchase intention

Based on theories in social psychology we can defined perceived convenient to use as the individual's perception that using the platform will allows consumers to carry out business activities anytime and anywhere. By ubiquity when is safe and simple manner. Similarly, Mathwick et al. (2012) [12] defined perceived usefulness as the extent to which a person deems a particular system to boost his or her job performance. As far Wechat app is most used in cell phone the mobility bring a big change compare to traditional online shopping.

H6: The perceived convenience of use is positively influencing the perceived ease of use.

H7: The perceived convenience of use is positively influencing online purchase intention through Wechat.

Many people will say they would not purchase or do some transactions through social network arguing about security for transactions and personal information privacy. Trust may be transferred from different types of sources. $\mathrm{Ba}$ (2001) [13] argued that although customers do not understand a website's operations or the quality of companies, they can use third-party site certification to judge the quality of the site. In social commerce, third parties services can transfer trust between sellers and consumers. The third-party services use certifications and payment guarantees to deliver trust known as third party stamp. With the wallet feature, Wechat users have to sync a real-world bank account to add credits and conduct transactions via Wechat pay. 
H8: Third party services moderate the effect of perceived ease of use on online purchase intention through Wechat.

H9: Third party services moderate the effect of perceived convenience of use on online purchase intention.

H10: Third party services are positively associated to the intention for online purchase.

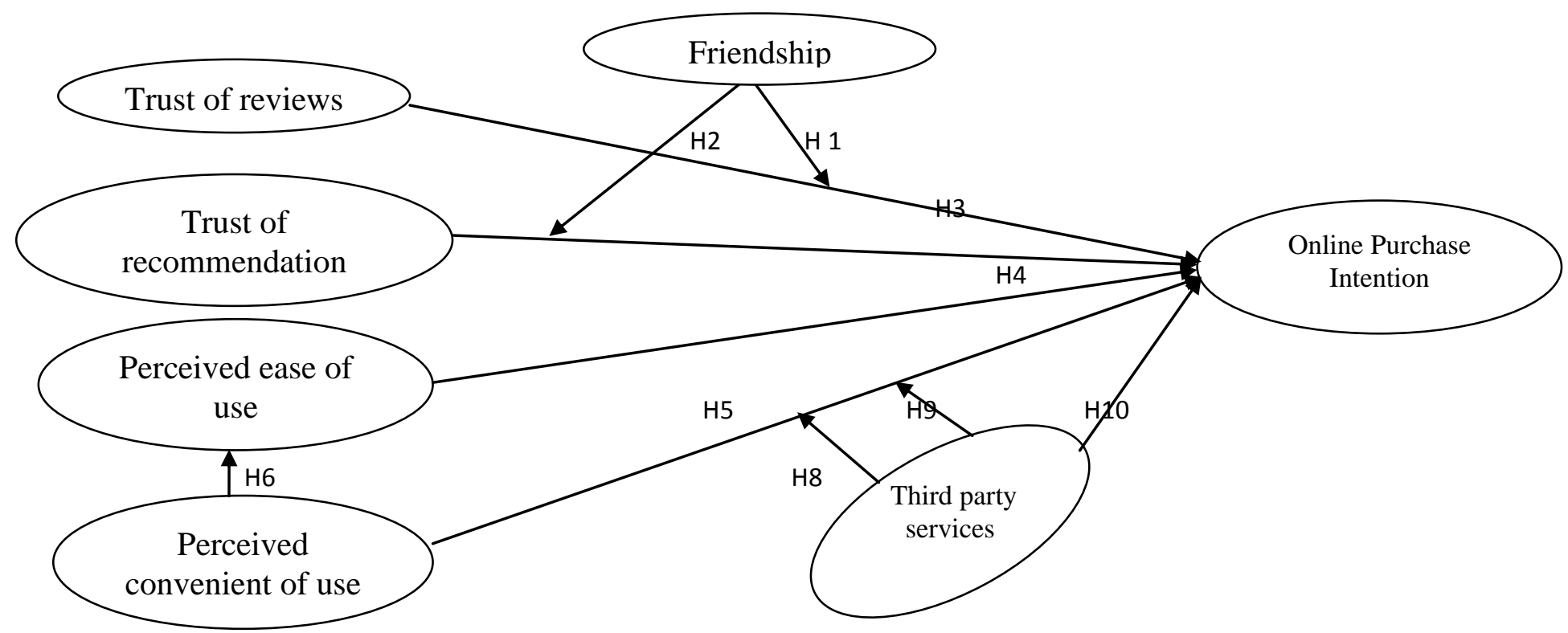

Figure1. Model research

\section{Data Collection, Findings and Implications}

Data Collection. The survey was conducted in China Beijing 2016 April where a questionnaire was only aimed at the ones who have a wechat account linked to bank account and had experience in online purchase and transaction. Finally around 250 responses were collected. We performed an initial screening for reliability and validity for all parameters. The demographic characteristic of the respondents are shown in Table I. Among the valid respondents, 117 were male (67\%) and 93 were female $(37 \%)$. Most of respondents were in their 20s (76\%) ages ranged between20-30. In addition their occupation: students 164(66\%); Professional workers 50 (20\%); Business persons 33 (13\%); Retired $3(1 \%)$. Moreover $66 \%$ means 164 of respondents spent more than an hour per day on Wechat social media. Such a demographic profile showed that the respondents were relatively young and generally active. This is consistent with previous investigations [14]. Apart about ethnic and demographical characteristics all other questionnaire items are measured on five point's likert-scale from strongly agree to strongly disagree.

Findings. The measurement model was assessed using structural equation modelling. We first examined the validity of the constructs and then tested the structural model based on the cleansed measurement model. In order to assess the reliability and convergent validity of our measurement model, we needed to check the factor loadings, the composite reliability (CR) and average variance extracted (AVE), as shown in Table II. All factors loading are above the desired threshold of 0.7. Expect for four indicators, FR3, FR4 PEU3, and PEU4, which satisfied the minimum requirement of 0.5 [15]. The composite reliability of our measurement ranged from 0.777 to 0.869 . These were all larger than 0.7, which means being acceptable [16]. The average variance extracted of our measurement ranged from 0.516 to 0.650 , which was above the recommended threshold of 0.5 [17]. Therefore, we had established convergent validity for the measurement model 
Table 1 Result of convergent validity

\begin{tabular}{|c|c|c|c|c|}
\hline Construct & Item & Factor loading & CR & AVE \\
\hline \multirow{4}{*}{ Friendship } & FR1 & 0.780 & \multirow[t]{4}{*}{0.809} & \multirow[t]{4}{*}{0.516} \\
\hline & FR2 & 0.776 & & \\
\hline & FR3 & 0.667 & & \\
\hline & FR4 & 0.640 & & \\
\hline \multirow[t]{3}{*}{ Trust of reviews } & TR1 & 0.807 & \multirow[t]{3}{*}{0.812} & \multirow[t]{3}{*}{0.640} \\
\hline & TR2 & 0.801 & & \\
\hline & TR3 & 0.791 & & \\
\hline \multirow{3}{*}{$\begin{array}{l}\text { Trust of } \\
\text { recommendations }\end{array}$} & TFR1 & 0.701 & \multirow[t]{3}{*}{0.777} & \multirow[t]{3}{*}{0.537} \\
\hline & TFR2 & 0.748 & & \\
\hline & TFR3 & 0.748 & & \\
\hline \multirow[t]{4}{*}{ Perceived of ease to use } & PEU1 & 0.823 & \multirow[t]{4}{*}{0.869} & \multirow[t]{4}{*}{0.624} \\
\hline & PEU2 & 0.809 & & \\
\hline & PEU3 & 0.785 & & \\
\hline & PEU4 & 0.739 & & \\
\hline \multirow{4}{*}{$\begin{array}{l}\text { Perceived of convenience } \\
\text { of use }\end{array}$} & PCU1 & 0.800 & \multirow[t]{4}{*}{0.815} & \multirow[t]{4}{*}{0.527} \\
\hline & PCU2 & 0.785 & & \\
\hline & PCU3 & 0.684 & & \\
\hline & PCU4 & 0.619 & & \\
\hline \multirow[t]{4}{*}{ Third parties services } & TPS1 & 0.779 & \multirow[t]{4}{*}{0.838} & \multirow[t]{4}{*}{0.565} \\
\hline & TPS2 & 0.761 & & \\
\hline & TPS3 & 0.747 & & \\
\hline & TPS4 & 0.718 & & \\
\hline \multirow[t]{4}{*}{ Intention online purchase } & IOP1 & 0.806 & \multirow[t]{4}{*}{0.860} & \multirow[t]{4}{*}{0.650} \\
\hline & IOP2 & 0.802 & & \\
\hline & IOP3 & 0.787 & & \\
\hline & IOP4 & 0.713 & & \\
\hline
\end{tabular}

Notes: $\mathrm{CR}=$ composite reliability; AVE =average variance extracted. . $* * * p<0.001$

The resulting estimations from PLS are shown in Figure 2 shows the standardized path coefficients of the research model. The model fits $\left(\mathrm{R}^{2}\right)$ show that friendship moderates the effect of trust for both reviews and recommendations and explained $23.1 \%$. Third party services moderates the effect of perceived convenience and perceived ease of use with $27.1 \%$. While the outcome factor intention online purchase has $46 \%$. The relationships among constructs are interpreted below.

Moderates effects of friendship to the trust of reviews and trust of recommendations from friends and firms

Friendship has moderate effect on trust of reviews and recommendations coefficients paths $(-0.533$; -0.066). This has a practical significance in social commerce by the fact that users not only rely on reviews found on social media neither recommendations from their friends or firms( companies) to intent online purchase or transactions but many factors are need to be settle down. H1and H2 Direct effects of trusts reviews and trust of recommendations, on the online purchase intention As in previous studies trust play an important role in online purchase The trusts of reviews and trust of recommendations have significant effects on online purchase intention as shown by the coefficient paths $(0.463 ;-0.063) \mathrm{H} 3$ and $\mathrm{H} 4$ 


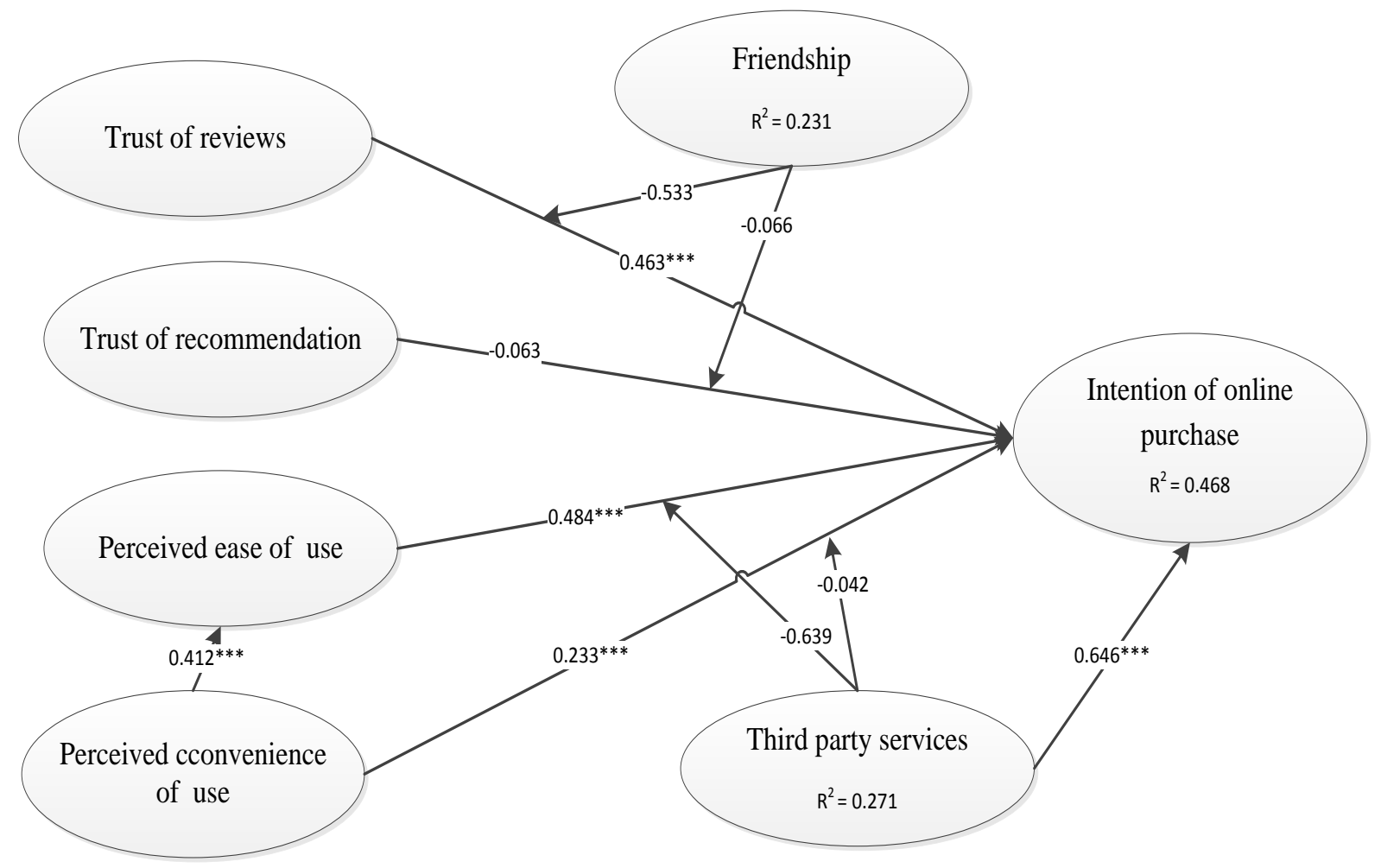

$* \mathrm{p}<0.05 ; * * \mathrm{p}<0.01 ; * * * \mathrm{p}<0.001$.

Figure 2. Estimated model

Direct effects of perceived convenience of use to the perceived ease of use; Perceived convenience of use have a significant effect on perceived ease of use as shown by the coefficients paths (0.412) H6

Direct effects of perceived ease of use and perceived convenience of use on online purchase intention

Perceived ease of use and perceived convenience of use have a significant effect on online purchase intention as shown by the coefficients paths $(0.484 ; 0.233)$ we can explain this by the fact that Wechat is easy to use and most used on Smartphone's which make it convenient to use from anywhere at any time. $\mathrm{H} 5$ and $\mathrm{H} 7$

Direct effects of third party services on the online purchase intention: the third party services have significant effects on online purchase intention as shown by the coefficient path coefficient (0.646); E-commerce will not be possible without the contribution of third party service. H10.

Moderating effects of third party services to the perceived ease of use and perceived convenience of use: third party services has a moderate effect perceived ease of use and convenience of use on to the intention online purchase coefficient paths $(-0.639 ;-0.0420)$. H8 and H9 were supported and show us that users not rely only on third parties services.

Implications. There are several important theoretical implications of this study. First, the impact of friendship should be employed to study in the online purchase and transactions context. Second due to the measurable characteristic of intention online purchase and transactions we prove the impact of perceived convenience of use. Third the results show us that perceived convenience of use can also affect positively the perceived ease of use. We have advanced e-WOM research by showing that a study regarding the online purchase and transactions can be tested by the impact of friendship as well. Most the perceived convenience of use sheds light on the existing of social commerce embedded in our daily life.

For practical implications the findings from this study hold important implications for sellers as well. First, the proposed value-based decision model for online purchase and transactions intention 
described a specific set of factors that retailers might manipulate to facilitate consumer purchasing. Second, this study empirically identified the moderating effects of third party services on perceived ease of use and perceived convenience of use in the intention online purchase and transactions context. Given that in this research perceived ease of use and perceived convenience of use are both associated with third party services, online marketing managers should attempt to balance the role of third party services perspective in online purchase and transactions. Finally, on the basis of our results, we suggest two strategies for the Wechat online businesses. One strategy is propaganda in order to let more Wechat users link their account to a bank account; sellers could stimulate consumers who had experience of online purchase and transactions to produce abundant credible recommendations and reviews. The other strategy may be promotion. Online marketing managers could provide promotion to bring more people to the adhesion for using Wechat pay as a convenient tool for their online purchase and transaction. As reported by walk talk the official website of Wechat the purchase initiated by Wechat double in one year Wechat users who has shopped in (2015) were 15\% to 31\% in May (2016). The top categories among Wechat shoppers are apparel (60\%) personal care (41\%).

\section{Conclusion and Limitations}

The popularity of social media has opened a new arena of business and research opportunities Trust creates positive attitudes toward online purchase and transactions as perceived convenience of use, ease of use, third party services does. Social commerce in China is evolving at break-neck speed, and social platforms such as Wechat are revolutionizing how business is conducted specially in China. With a rapidly growing user base, Wechat is becoming a one-stop-shop for all Smartphone owners and is offering huge opportunities for brands to connect with their fans. Future research could examine some additional factors, such as promotion information, security of privacy, and interaction with retailers. A research model that combines more social interaction and more technical features support could be investigated to extend this work. The outcome variable may also be the observed behaviour, rather than the intention.

The limitations of the study must be acknowledged, which can open up opportunities for future research. First, with respect to external validity, the empirical results obtained in this study are based on the online purchasing and transactions through Wechat (social media) most used in China and start expending around the world. The context may not generalize others research of online purchasing and transaction. Furthermore, the respondents were Chinese and Foreigners living in China with a Wechat account linked to a local Chinese bank. We reviewed some former studies and proposed hypotheses based on them. Through an online questionnaire survey, we collected data from the biggest social media in China. The discriminate and convergent validity of the constructs were examined using factor analysis procedure based on structural equation modelling. Moreover, the online purchase intention output might be different according to the different factors. Therefore, the entire research context is focus online purchasing intention through only Wechat. With respect to the variances of the research model, the intention online purchase cannot be fully assessed.

\section{Acknowledgements}

This work is partially supported by Natural Science Foundation of China (Project No. 71271012 and 71332003).

\section{References}

[1] Liang, T., Ho, Y., and Li, Y. What drives social commerce: The role of social support and relationship quality? International Journal of Electronic Commerce, 16(2), 69-90, 2012 
[2] Dan J. Kim, Donald L. Ferrin, H. Raghav Rao A trust-based consumer decision-making model in electronic commerce: The role of trust, perceived risk, and their antecedents, Decision Support Systems 44, 544-564, 2008.

[3] Wilson, L., Izak, B. Designing an electronic commerce interface. Attention and product memory as elicited by web design. Electronic Commerce Research and Applications, autumn, Pages 240-253, 2003

[4] Siau, K., and Shen, Z. Building customer trust in mobile commerce. Communications of the ACM, 46(4), 91-94, 2003

[5] Marios, K., and William, H-S. The development of initial trust in an online company by new customers Information \& Management Volume 41, Issue 3, Pages 377-397, 2004

[6] Chen, J. Xu, $\mathrm{H}$ and Whinston, A.B. Moderated online communities and quality of user-generated content Journal of management information systems.28 (2), 237-268, 2011

[7] Chen Y.B. and Xie J.H. Third-Party product review and firm marketing strategy. Marketing Science 24(2), 218-240, 2005

[8] Fuller, J, Muhlbacher, H., Matzler, K., and Jawecki, G. Consumer empowerment through internet-based co-creation. Journal of management Information systems 26(3), 71-102, 2009

[9] Dunay P. and Krueger R. Facebook Marketing for Dummies, For Dummies Publishing, NY, 2009.

[10] Wu, H., and Wang, J. An empirical study of flow experiences in social network sites. In The 15th Pacific Asia Conference on Information systems (PACIS) Queensland University of Technology, Australia, (2011)

[11] Ammar, N., Rosnafisah, S., Asmidar, A, B.A review Factors Influencing Individuals Trust in Online Purchase through Social Networking Sites; Putrajaya, Malaysia, 2014.

[12] Mathwick, C., Wiertz, C., De Ruyter, K. Social capital production in a virtual P3 community. J. Consumer. Res. 34 (6), 832-849, 2008

[13] Ba, S. Establishing online trust through a community responsibility system. Decision Support Systems, 3(31), 323-336, 2001

[14]Zhang, K.Z.K., Zhao, S.J., Cheung, C.M.K. and Lee, M.K.O. "Examining the influence of online reviews on consumers' decision-making: a heuristic-systematic model", Decision Support Systems, Vol. 67 No. 1, pp. 78-89, 2014.

[15] Cannon, J. P. and Homburg, C. Buyer-supplier Relationships and Customer Firm Costs, Journal of Marketing 65, pp. 29-43, 2001.

[16] Hair, J. T., Anderson, R. E., Tatham, R. L. and Black, W. C .Multivariate Data Analysis, Upper Saddle River, NJ: Prentice Hall, pp.1-730, 1998.

[17]Fornell, C. and Larcker, D. F. Evaluating Structural Equation Models with Unobservable Variables and Measurement Error, Journal of Marketing Research, (18:2), pp.39-50, 1981. 